\title{
PERAN BRAND IMAGE SEBAGAI MEDIATOR ANTARA COUNTRY OF ORIGIN DENGAN PURCHASE INTENTION
}

\author{
Ida Bgs Hendra Prawira Kusuma ${ }^{1}$ \\ I Gusti Ayu Ketut Giantari ${ }^{2}$ \\ ${ }^{1,2}$ Fakultas Ekonomi dan Bisnis Universitas Udayana, Bali, Indonesia \\ e-mail: hendraprawira96@gmail.com
}

\begin{abstract}
ABSTRAK
Penelitian ini bertujuan untuk menjelaskan peran brand image dalam memediasi hubungan country of origin dengan purchase intention. Penelitian dilakukan di kota Denpasar dengan jumlah sampel sebanyak 120 responden yang belum pernah membeli produk mobil Isuzu. Sampel ditentukan menggunakan model non-probability sampling, dengan teknik purposive sampling. Teknik analisis data yang digunakan adalah analisis jalur dan uji sobel. Hasil penelitian menunjukkan bahwa seluruh hipotesis diterima. Country of origin berpengaruh positif dan signifikan terhadap brand image, country of origin berpengaruh positif dan signifikan terhadap purchase intention, brand image berpengaruh positif dan signifikan terhadap purchase intention, brand image memediasi pengaruh country of origin terhadap purchase intention. Perusahaan diharapkan kedepannya memanfaatkan country of origin dari perusahaan Isuzu yaitu Jepang untuk sarana mempromosikan produk mobil Isuzu agar mampu membuat konsumen percaya pada produk yang perusahaan tawarkan sehingga dapat berdampak pada timbulnya purchase intention.
\end{abstract}

Kata kunci: country of origin, brand image, purchase intention

\begin{abstract}
This research aims to clarify the role of the brand image in the mediated relationship of country of origin with the purchase intention. Research conducted in the city of Denpasar with number of samples as much as 120 respondents who have never bought a car Engine products. The sample was determined using a model of non-probability sampling, with the technique of purposive sampling. Data analysis technique used is a path analysis and test sobel. The results showed that the hypothesis is accepted. Country of origin effect positively and significantly to the brand image, country of origin effect positively and significantly to purchase intention, brand image and positive effect significantly to purchase intention, brand image mediate the influence of country of origin against the purchase intention. The company's expected future make use of country of origin of the company namely Isuzu Japan for means of promoting products to Isuzu cars make consumers believe the company's offer on the product so that it can have an impact on the incidence of purchase intention.
\end{abstract}

Keywords: country of origin, brand image, purchase intention 
Ida Bgs Hendra Prawira Kusuma, Peran Brand Image Sebagai ...

\section{PENDAHULUAN}

Perkembangan yang sangat pesat terjadi di berbagai bidang di seluruh dunia, baik dalam perkembangan di bidang teknologi, transportasi dan komunikasi. Bukti tersebut dapat dilihat dari semakin banyaknya penggunan transportasi di sekitar kita. Transportasi merupakan kebutuhan pokok bagi semua orang, baik itu transportasi darat, laut maupun udara. Sebab transportasi dapat mempermudah mobilisasi seseorang dari satu tempat menuju ke tempat yang lain dengan mudah dan cepat. Namun transportasi darat yang memiliki peran lebih besar dalam kehidupan sehari-hari dibandingkan jenis transportasi lainnya.

Mobil merupakan salah satu transportasi darat yang menjadi pilihan utama masyarakat. Banyak sekali pilihan untuk mobil dengan tujuan mengangkut banyak anggota keluarga, tapi tak jarang pula mobil yang biasanya digunakan untuk membawa anggota keluarga tersebut digunakan untuk kegiatan memutar uang. Seperti menjadikan mobil tersebut sebagai taksi, travel, angkutan barang dan lain sebagainya. Sehingga konsumen yang membeli mobil tersebut memiliki dua manfaat, selain bisa menggunakannya untuk pribadi, juga bisa digunakan untuk berniaga. Mobil niaga merupakan mobil yang digunakan untuk kegiatan jual beli dan untuk memperoleh keuntungan.

Umumnya, mobil - mobil yang digunakan untuk berniaga tersebut adalah mobil dengan harga yang terjangkau, konsumsi BBM irit, perawatan mudah serta yang lebih penting yaitu memiliki kapasitas besar yang mampu memuat banyak barang. Bukan hanya soal kapasitas bak yang sanggup menampung banyak barang saja, kemampuan mesin yang tangguh pun wajib diperhitungkan demi menjajaki 
medan di Indonesia yang berbukit atau pegunungan. Tidak sembarang mobil dapat digunakan untuk mengangkut dan memuat barang dagangan.

Mesin diesel adalah sebuah mesin pemicu kompresi dimana bahan bakar dinyalakan dengan suhu gas yang tinggi yang dikompresikan dan tidak menggunakan mesin berenergi seperti busi. Pada dasarnya mesin diesel ini bekerja dengan cara merubah energi kimia menjadi energi mekanis. Energi kimia tersebut didapatkan memalui proses pembakaran bahan bakar solar dan oksidiser (udara) di dalam silinder (ruang bakar).

Mobil dengan mesin diesel memiliki beberapa keunggulan diantaranya adalah mesin diesel memiliki efisiensi panas yang tinggi, bahan bakarnya lebih hemat yang berarti bahwa mesin diesel lebih sedikit mengkonsumsi bahan bakar dibanding mesin bensin untuk menyediakan tenaga yang sama, biaya operasional yang lebih murah, mesin diesel lebih tahan lama dan tidak memerlukan instalasi pengapian, sehingga gangguan-gangguan yang terjadi lebih kecil dibanding dengan mesin bensin. Momen yang dihasilkan mesin diesel lebih besar dibanding mesin bensin (Riyadi, 2012).

Mobil yang biasanya menggunakan mesin diesel adalah mobil - mobil dengan kapasitas besar dan tenaga yang besar, beberapa diantaranya adalah jenis MPV (Multi Purpose Vehicle), pick up, double cabin, bus dan truk. Di Indonesia mobil dengan mesin diesel cukup banyak memiliki peminat, karena sebagian besar penduduk Indonesia bekerja sebagai petani, berkebun, berniaga dan sebagian lainnya bekerja sebagai pelaku pariwisata. Semua pekerjaan tersebut memerlukan angkutan, angkutan yang dipilih umumnya yang mempunyai nilai 
Ida Bgs Hendra Prawira Kusuma, Peran Brand Image Sebagai ...

ekonimis tinggi baik di bidang kualitas mesin maupun efisiensi dalam penggunaan BBM. Pick up dan truk menjadi pilihan untuk angkutan barang dan hasil perkebunan, kedua jenis angkutan tersebut dijadikan kendaraan utama karena mampu mengangkut barang dengan jumlah yang relatif banyak serta mampu melewati berbagai medan. Disisi lain para pelaku pariwisata juga lebih berminat menggunakan angkutan yang mempunyai nilai ekonomis tinggi dalam hal memiliki mesin yang tangguh body yang relatif longgar dan nyaman serta penggunaan BBM yang irit karena bahan bakar minyak yang dipakai adalah bahan bakar jenis solar.

Pada tahun 1937 Isuzu dikembangkan pertama kali di Jepang. Isuzu telah menjadi pengembang mesin diesel terkemuka di tingkat global serta berperan penting pada industrinya, salah satunya sebagai kendaraan niaga. Dalam suatu artikel di www.otomotif.liputan6.com (Agustus 2014) dinyatakan bahwa Isuzu Panther merupakan salah satu mobil yang paling irit di tanah air berfitur tujuh kursi penumpang yang unggul dalam hal fungsionalitas dan efisiensi bahan bakar yang bisa diandalkan. Isuzu pada saat ini berada di bawah naungan PT. Isuzu Astra Motor Indonesia (IAMI). 
Tabel 1.

\begin{tabular}{cccc}
\multicolumn{3}{c}{ Penjualan Mobil di Indonesia dari Tahun 2014 sampai Tahun 2016 } \\
\hline \multirow{3}{*}{ Merek } & \multicolumn{3}{c}{ Penjualan (Unit) } \\
\cline { 2 - 4 } & Tahun 2014 & Tahun 2015 & Tahun 2016 \\
\hline Toyota & 399.119 & 321.818 & 381.570 \\
Daihatsu & 185.226 & 167.808 & 189.683 \\
Honda & 159.147 & 159.253 & 199.364 \\
Suzuki & 154.923 & 121.805 & 92.950 \\
Mitsubishi & 141.962 & 112.527 & 66.443 \\
Datsun & 20.520 & 29.358 & 25.483 \\
Nissan & 33.789 & 25.108 & 13.153 \\
Hino & 28.493 & 21.576 & 21.903 \\
Isuzu & 28.278 & 19.350 & 16.848 \\
Mazda & 9.230 & 8.859 & 5.107 \\
\hline
\end{tabular}

Sumber: www.gaikindo.org.id

Perbedaan tingkat penjualan dapat dilihat pada merek mobil yang berasal dari Jepang dan merek mobil dari negara lainnya. Hal ini memiliki arti bila penjualan mobil yang ada di Indonesia didominasi oleh mobil asal Jepang yaitu salah satunya adalah Isuzu. Walaupun hanya menempati peringkat ke sembilan, Isuzu masih dipercaya oleh sebagian besar penduduk di Indonesia untuk dijadikan sebagai mobil niaga dibandingkan merek mobil lainnya, yang berarti terdapat kepercayaan konsumen yang baik terhadap mobil merek Isuzu, sehingga dibenak konsumen, citra merek yang baik dimiliki oleh mobil merek Isuzu.

Isuzu adalah salah satu dari sekian banyak produsen mobil raksasa. Selain itu Isuzu juga merupakan satu - satunya produsen mobil yang hanya khusus memproduksi mobil bermesin diesel, mesin diesel milik Isuzu terkenal sangat tangguh dan irit itu sebabnya Isuzu dijuluki sebagai "rajanya diesel". Dewasa ini ini konsumen lebih banyak memilih produk tidak hanya dilihat dari fitur dan kualitas produknya saja tetapi brand image merupakan nilai tambah dari sebuah perusahaan untuk dapat menjual produknya. 
Ida Bgs Hendra Prawira Kusuma, Peran Brand Image Sebagai ...

Produk dengan brand image yang baik dapat menciptakan nilai emosional konsumen sehingga brand image perlu untuk diperhatikan oleh perusahaan. Nilai emosional dapat menciptakan persepsi positif terhadap suatu produk. Brand image dapat menciptakan pembelian berulang kareana brand image yang baik secara emosional dapat menciptakan rasa puas pada konsumen yang akan menghasilkan kesan kualitas terhadap suatu merek (Maunaza, 2012).

Tolak ukur konsumen sebelum memutuskan untuk melakukan pembelian produk yaitu merk, desain, harga dan kualitas adalah hal yang penting untuk diperhitungkan, namun faktor eksternal seperti country of origin tidak dapat diabaikan konsumen dalam menentukan pembelian suatu produk. Country of origin adalah negara tempat berasalnyal suatu produk yang secara umum dianggap sebagai bagian dari karakteristik suatu produk (Hong dan Wyer, dalam Permana, 2013).

Tabel 2.

Survei Top Brand Index Kategori Mobil Niaga 2017

\begin{tabular}{ccc}
\hline Merek & TBI $(\%)$ & TOP \\
\hline Mitsubishi & 23,8 & TOP \\
Daihatsu & 21,9 & TOP \\
Isuzu & 14,3 & TOP \\
Hino & 11,1 & \\
Toyota & 10,2 & \\
Suzuki & 5,9 & \\
Sumber: & www.topbrand-award.com &
\end{tabular}

Sumber: www.topbrand-award.com

Mobil niaga merek Isuzu menempati urutan ketiga dalam survey Top Brand Index sepanjang tahun 2017, meskipun Isuzu berada pada tingkat ketiga diungguli Mitsubishi dan Daihatsu, Isuzu masih masuk dalam kategori TOP di bidang mobil niaga. Hal ini menunjukkan bahwa citra merek terhadap mobil merek Isuzu masih baik dibenak konsumen. Perbedaan tingkat penjualan dapat dilihat antara merek 
mobil yang berasal dari Negara Jepang dan merek mobil yang berasal dari Negara lainnya. Pembelian mobil oleh sebagian besar masyarakan adalah berasal dari merek Jepang daripada merek lain yang berasal dari Negara lainnya Persepsi dari country of origin dapat mempengaruhi secara langsung ataupun tidak secara langsung bagaimana pengambilan keputusan yang dilakukan konsumen untuk memilih dan menggunakan suatu produk.

Isu mengenai country of origin telah menarik perhatian untuk diteliti. Banyak peneliti melakukan penelitian yang serupa, seperti penelitian oleh Arimbawa dan Rahuyda (2015) menemukan bila country of origin memiliki pengaruh positif dan signifikan terhadap purchase intention. Penelitian oleh Mira dan Yasa (2015) yang menyatakan bila country of origin memiliki pengaruh positif terhadap brand image. Melalui country of origin diharapkan dapat meningkatkan brand image yang secara tidak langsung dapat meningkatkan purchase intention. Namun penelitian dari Wahyuni (2016) menemukan, bila country of origin tidak berpengaruh terhadap minat beli konsumen. Hasil yang tidak konsisten ini mendorong peneliti untuk melakukan penelitian lebih lanjut yang melibatkan variabel brand image sebagai mediasi dalam mempengaruhi country of origin terhadap purchase intention. Untuk kebaruan dalam penelitian ini adalah penelitian ini belum pernah dilakukan oleh peneliti sebelumnya yang meneliti tentang peran brand image sebagai mediator antara country of origin dengan purchase intention pada produk mobil Isuzu di kota Denpasar. Diharapkan penelitian ini dapat memberikan jawaban atas semua hipotesis yang dibuat oleh peneliti, agar dapat berguna bagi pihak-pihak yang membutuhkan. 
Ida Bgs Hendra Prawira Kusuma, Peran Brand Image Sebagai ...

Berdasarkan latar belakang tersebut, maka rumusan masalah penelitian ini adalah 1) Bagaimana pengaruh country of origin terhadap brand image mobil merek Isuzu di Kota Denpasar? ; 2) Bagaimana pengaruh country of origin terhadap purchase intention mobil merek Isuzu di Kota Denpasar? ; 3) Bagaimana pengaruh brand image terhadap purchase intention mobil merek Isuzu di Kota Denpasar? ; 4) Bagaimana peran brand image dalam memediasi pengaruh country of origin terhadap purchase intention mobil merek Isuzu di Kota Denpasar?

Tujuan penelitian ini antara lain 1) Untuk menjelaskan pengaruh country of origin terhadap brand image mobil merek Isuzu di Kota Denpasar ; 2) Untuk menjelaskan pengaruh country of origin terhadap purchase intention mobil merek Isuzu di Kota Denpasar ; 3) Untuk menjelaskan pengaruh brand image terhadap purchase intention mobil merek Isuzu di Kota Denpasar ; 4) Untuk menjelaskan peran brand image dalam memediasi pengaruh country of origin terhadap purchase intention mobil merek Isuzu di Kota Denpasar.

Manfaat penelitian ini ada dua, pertama manfaat teoretis, hasil penelitian ini diharapkan dapat memperluas wawasan dan pengetahuan serta bukti empiris terkait variabel yang diteliti. Penelitian ini juga diharapkan akan dapat menjadi referensi bagi peneliti yang akan melakukan penelitian terkait. Manfaat praktis, hasil dari penelitian ini diharapkan dapat dijadikan sebagai bahan pertimbangan dan masukan, sehingga dapat dijadikan acuan serta referensi terhadap perusahaan Isuzu yang berkaitan dengan peran brand image dalam memediasi pengaruh country of origin terhadap purchase intention. 
Peneliti menggunakan konsep country of origin image untuk mengukur country of origin berdasarkan Laroche et al. (2005) yang terdiri dari 3 komponen utama, yaitu country beliefs, people affect dan desired interaction, Sehingga country of origin adalah salah satu dasar pertimbangan bagi konsumen sebelum memutuskan untuk melakukan pembelian atas suatu produk, semakin positif citra merek maka minat membeli akan semakin meningkat karena konsumen memiliki persepsi bahwa semakin baik citra dari negara asal, sehingga semakin baik pula kualitas produk. Sebaliknya apabila citra negara asal buruk, hal ini tentu saja akan mengurangi minat konsumen untuk membeli produk.

Brand image adalah sebuah persepsi tentang merek yang dihubungkan dengan asosiasi merek yang melekat dalam ingatan konsumen (Rangkuti, 2009). Saat suatu merek mempunyai suatu citra yang positif maka merek tersebut menjadi semakin diingat oleh konsumen dan dapat mempengaruhi pembelian konsumen (Musay, 2013). Menurut Sutisna (2010), brand image memiliki 3 variabel pendukung, yaitu corporate image, user image, product image. Sehingga brand image kemudian menjadi salah satu daya tarik konsumen dari suatu produk. Brand image yang nantinya positif ini nantinya akan meningkatkan keinginan konsumen untuk membeli suatu produk.

Niat beli adalah tahap kecenderungan responden untuk bertindak sebelum benar-benar melakukan pembelian (Kinnear, 1995). Menurut Wijaya (2011) indikator minat beli adalah melalui model stimulasi AIDA yang berusaha memberikan gambaran langkah-langkah rangsangan yang mungkin dilalui oleh konsumen yang diberikan oleh pemasar, yaitu Attention, Interest, Desire, Action. 
Niat yang timbul ketika melakukan pembelian menimbulkan motivasi yang akan terus terekam dalam benak konsumen (Rahma, 2007).

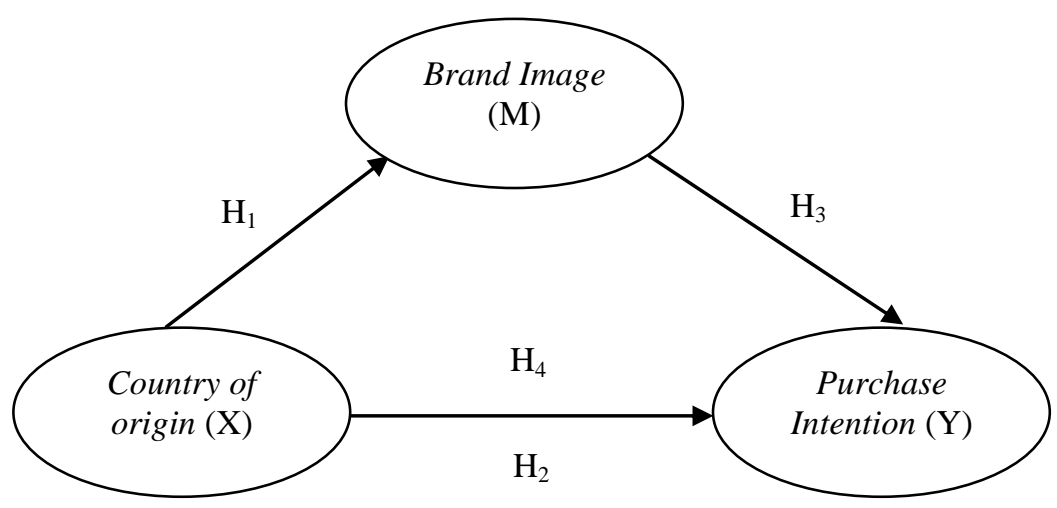

\section{Gambar 1. Kerangka Konseptual Penelitian}

Sumber: Bhakar et al., 2013

Penelitian terdahulu oleh Permana (2013) dan penelitian yang dilakukan oleh Yamen Kuoba (2008) dan Diamantopoulos et al. (2011) berpendapat bahwa country of origin berdampak positif dan signifikan terhadap brand image, yang artinya semakin baik citra dari suatu negara dapat memberikan dampak positif terhadap citra dari merek tersebut.

$\mathrm{H}_{1}$ : Country of origin berpengaruh positif dan signifikan terhadap Brand Image.

Susanti dan Kustijana (2010) menyatakan apabila persepsi akan country of origin konsumen baik maka akan memiliki pengaruh terhadap niat pembelian, hal tersebut didukung oleh penelitian Wang dan Yang (2008) dan penelitian Chih et al. (2013) mengatakan bahwa country of origin berdampak positif dan signifikan terhadap purchase intention.

$\mathrm{H}_{2}$ : Country of origin berpengaruh positif dan signifikan terhadap Purchase Intention.

Penelitian oleh Semuel dan Lianto (2014) mengatakan bahwa brand image yang baik pada produk smartphone berpengaruh kepada minat beli konsumen. Hal 
ini disebabkan karena konsumen telah mengetahui keuntungan yang akan didapatkan dan merek dari produk smartphone yang akan dibelinya. Hal ini juga didukung oleh penelitian Bhakar et al. (2013) yang menyatakan bahwa, brand image berpengaruh signifikan terhadap niat membeli. Hasil yang sama ditemukan oleh penelitian Yu et al. (2013) ; Maunaza (2012) dan Shah et al. (2012) yang menyatakan bila brand image memiliki pengaruh positif terhadap niat membeli konsumen.

$\mathrm{H}_{3}$ : Brand image berpengaruh positif dan signifikan terhadap Purchase Intention.

Country of origin image memiliki pengaruh tidak langsung terhadap niat membeli dan dalam pengaruhnya sepenuhnya dimediasi oleh brand image (Diamantopoulos et al., 2011). Country of origin memiliki pengaruh tidak signifikan terhadap purchase intention apabila hubungan terjadi secara langsung. Namun perbedaan terjadi ketika country of origin diterapkan bersamaan dengan brand image terhadap purchase intention maka akan memperoleh hasil positif dan signifikan (Bhakar et al., 2013)

$\mathrm{H}_{4}$ : Brand image memediasi Country of origin terhadap Purchase Intention.

\section{METODE PENELITIAN}

Penelitian ini menggunakan pendekatan kuantitatif yang termasuk jenis penelitian asosiatif. Asosiatif mampu menjelaskan hubungan antara variabel satu terhadap variabel lainnya. Penelitian ini dilakukan untuk menjelaskan hubungan pengaruh variabel country of origin dan brand image terhadap purchase intention pada mobil merek Isuzu di Kota Denpasar. Penelitian yang dilakukan berlokasi di 
Ida Bgs Hendra Prawira Kusuma, Peran Brand Image Sebagai ...

Kota Denpasar. Kota Denpasar dipilih karena kota ini merupakan ibukota dari Provinsi Bali. Selain itu juga Kota Denpasar dipilih karena melihat dari masyarakatnya yang heterogen, berasal dari berbagai daerah lain di Provinsi Bali. Penelitian ini menggunakan variabel bebas yaitu country of origin, variabel mediasi yaitu brand image dan variabel terikat yaitu purchase intention.

Tabel 3.

Indikator Penelitian

\begin{tabular}{|c|c|c|}
\hline Variabel & Indikator & Sumber \\
\hline $\begin{array}{l}\text { Country of Origin } \\
(\mathbf{X})\end{array}$ & 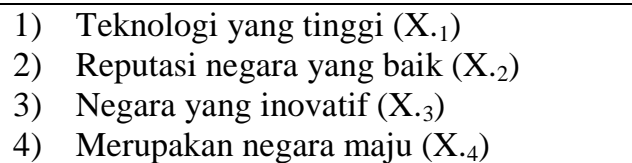 & $\begin{array}{l}\text { Yasin et al. } \\
\quad(2007)\end{array}$ \\
\hline Brand Image $(\mathrm{M})$ & $\begin{array}{l}\text { 1) } \text { Merek yang kuat }\left(\mathrm{M}_{\cdot 1}\right) \\
\text { 2) } \text { Coorporate image }\left(\mathrm{M}_{2}\right) \\
\text { 3) } \text { Product image }\left(\mathrm{M}_{\cdot 3}\right) \\
\text { 4) } \text { Kemasan dan desain yang baik }\left(\mathrm{M}_{\cdot}\right)\end{array}$ & Permana (2013) \\
\hline $\begin{array}{l}\text { Purchase Intention } \\
\text { (Y) }\end{array}$ & $\begin{array}{l}\text { 1) Kesadaran akan eksistensi produk (Y.1) } \\
\text { 2) Ketertarikan untuk mencoba }\left(\mathrm{Y}_{2}\right) \\
\text { 3) Mencari informasi tentang harga }\left(\mathrm{Y}_{\cdot 3}\right) \\
\text { 4) Keinginan segera membeli }(\mathrm{Y} \cdot 4)\end{array}$ & $\begin{array}{c}\text { Calvin dan } \\
\text { Samuel (2014) }\end{array}$ \\
\hline
\end{tabular}

Populasi dalam penelitian ini adalah calon pembeli dari mobil merek Isuzu di Kota Denpasar. Populasi yang digunakan pada penelitian ini adalah konsumen yang belum pernah membeli mobil merek Isuzu. Sampel yang digunakan dalam penelitian ini adalah masyarakat Kota Denpasar yang belum pernah membeli produk mobil merek Isuzu. Metode penentuan sampel dalam penelitian menggunakan non probability sampling yaitu teknik pengambilan sampel yang tidak memberi peluang atau kesempatan yang sama bagi setiap unsur atau anggota populasi untuk dipilih menjadi sampel (Rahyuda dkk, 2004). Teknik non probability sampling yang dipilih adalah purposive sampling yaitu teknik penentuan sampel dengan pertimbangan tertentu. 
Kriteria sampel dalam penelitian ini adalah sebagai berikut: 1) Responden yang telah menempuh pendidikan terakhir minimal SMA/SMK sederajat. Pertimbangan tersebut ditentukan bahwa dengan jenjang pendidikan terakhir SMA/SMK sudah mampu memahami isi kuisioner ; 2) Responden yang berdomisili di Kota Denpasar dan 3) Responden yang belum pernah membeli mobil Isuzu. Penelitian ini dianalisis dengan multivariate dalam melakukan analisis, maka jumlah anggota sampel minimal 10 kali dari jumlah indikator yang akan diteliti (Sugiyono, 2014: 129). Jumlah indikator yang akan digunakan berjumlah 12 sehingga jumlah sampel yang digunakan adalah $12 \times 10=120$ responden. Pengumpulan data dalam penelitian ini dengan melakukan penyebaran instrumen penelitian yang menggunakan kuisioner. Kuisioner terdiri dari pertanyaan terbuka dan pertanyaan tertutup. Pertanyaan terbuka berupa identitas responden seperti nama, usia, pekerjaan responden. Sedangkan, pertanyaan tertutup berupa pertanyaan terkait indikator variabel penelitian dengan opsi jawaban yang telah ditentukan dan diukur dengan menggunakan 1 sampai 5 Skala Likert, dengan keterangan dalam tabel berikut.

Tabel 4.

Alternatif Jawaban Responden

\begin{tabular}{lcc}
\hline \multicolumn{1}{c}{ Jawaban } & Kode & Skor \\
\hline Sangat Setuju & SS & 5 \\
Setuju & ST & 4 \\
Cukup Setuju & CS & 3 \\
Tidak Setuju & TS & 2 \\
Sangat Tidak Setuju & STS & 1 \\
\hline Sumber: Sugiyono, 2014 & &
\end{tabular}

Jenis data yang digunakan dalam penelitian ini, yaitu Data Kuantitatif yang terdiri dari usia responden dan hasil pengolahan data SPSS yang digunakan untuk 
mengetahui hasil dari hubungan antar variabel. Data kualitatif pada penelitian ini adalah pendapat responden terhadap pernyataan yang meliputi country of origin, brand image, dan purchase intention. Adapun sumber data yang digunakan dalam penelitian ini adalah sumber primer, yaitu sumber yang berasal dari responden secara langsung. Sumber sekunder penelitian ini yaitu sumber yang berasal dari pihak lain yang mempublikasikan data yang dikutip terkait dengan topik penelitian ini.

Teknik analisis data dalam penelitian ini menggunakan Analisis statistik deskriptif. Selain itu dalam penelitian ini teknik analisis yang digunakan adalah teknik analisis jalur (path analysis). Ghozali (2013:249) mendefinisikan analisis jalur (path analysis) adalah perluasan dari analisis regresi linear berganda dalam memperkirakan hubungan kausalitas antara variabel yang telah ditetapkan sebelumnya berdasarkan teori.

Ridwan dan Kuncoro (2011:152) menyebutkan langkah - langkah dalam menganalisis data dengan mengunakan path analysis sebagai berikut: 1) Merumuskan hipotesis dan persamaan struktural, yaitu Variabel country of origin (X) berpengaruh terhadap brand image (M), Varibel brand image (M) berpengaruh terhadap purchase intention (Y), Variabel country of origin (X) berpengaruh terhadap purchase intention (Y), Variabel country of origin (X) berpengaruh terhadap variabel purchase intention (Y) melalui variabel brand image (M).

Sub-struktural 1

$\mathrm{M}=\beta_{1} \mathrm{X}+\mathrm{e}$ 
Sub-struktural 2

$\mathrm{Y}=\beta_{2} \mathrm{X}+\beta_{3} \mathrm{M}+\mathrm{e}$

Keterangan :

\begin{tabular}{|c|c|}
\hline Y & $=$ purchase intention \\
\hline$X$ & $=$ country of origin \\
\hline M & $=$ brand image \\
\hline$\beta_{1}, \beta_{2}, \beta_{3}$ & $\begin{array}{l}=\text { koefisien regresi variabel } \\
=\text { error }\end{array}$ \\
\hline
\end{tabular}

Pengaruh langsung (direct effect) terdiri dari pengaruh variabel country of origin $(\mathrm{X})$ terhadap brand image $(\mathrm{M})$ sebesar $\beta_{1}$, pengaruh variabel country of origin $(\mathrm{X})$ terhadap purchase intention $(\mathrm{Y})$ sebesar $\beta_{2}$, Pengaruh variabel brand image $(\mathrm{M})$ terhadap purchase intention $(\mathrm{Y})$ sebesar $\beta_{3}$. Pengaruh tidak langsung (indirect effect ) yaitu pengaruh variabel country of origin (X) terhadap purchase intention (Y) dengan brand image (M) sebagai variabel mediasi sebesar:

Pengaruh tidak langsung $=\beta_{2} \times \beta_{3}+\mathrm{e}$

Total pengaruh variabel country of origin $(\mathrm{X})$ terhadap purchase intention (Y) melalui brand image (M) dirumuskan sebagai berikut :

Total efek $=\beta_{1}+\left(\beta_{2} \times \beta_{3}\right)+$ e.

$$
\begin{aligned}
& \mathrm{X}=\text { country of origin } \\
& \mathrm{M} \quad=\text { brand image } \\
& \mathrm{Y}=\text { purchase intention }
\end{aligned}
$$

$\varepsilon_{1}\left(\right.$ error $\left._{1}\right)=$ menunjukkan jumlah varian brand image yang tidak dijelaskan oleh country of origin.

$\left(\varepsilon_{1}=\sqrt{ } 1-\mathrm{R}^{2}\right)$

$\varepsilon_{2}\left(\right.$ error $\left._{2}\right)=$ menunjukkan jumlah varian purchase intention yang tidak dijelaskan oleh country of origin. 


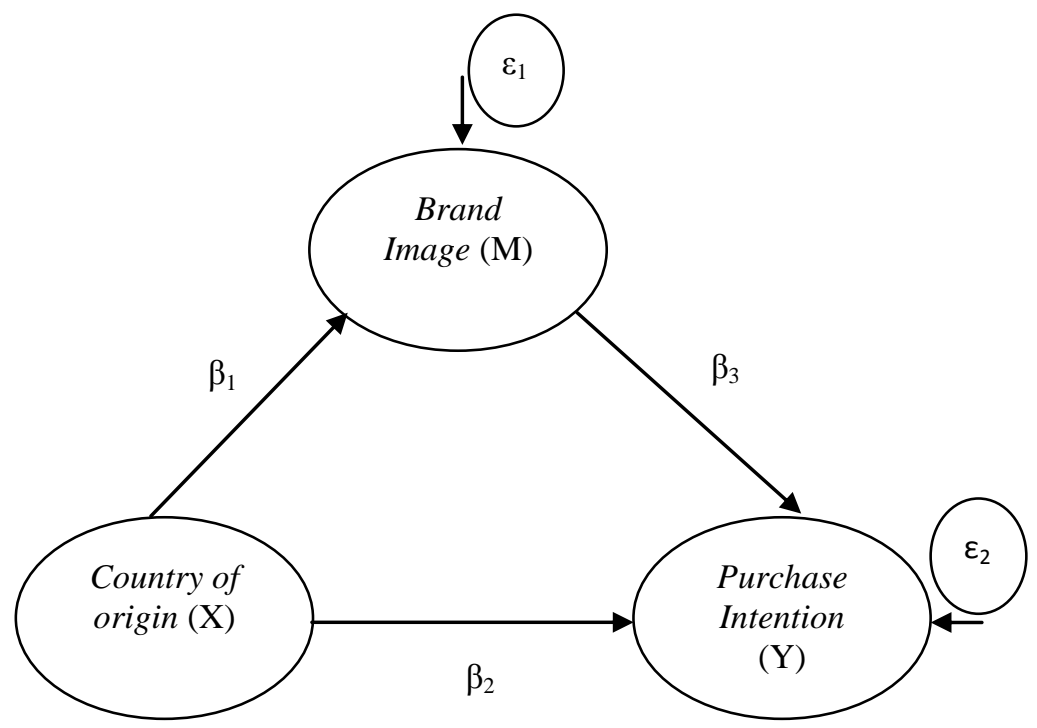

\section{Gambar 2. Diagram Koefisien Jalur}

Sumber: Gambar diolah, 2018

Menghitung koefisien jalur secara simultan (keseluruhan) dirumuskan sebagai berikut :

Ho : $\rho \mathrm{y} 2 \mathrm{x}=\rho \mathrm{y} 2 \mathrm{y} 1=0$

$\mathrm{H}_{1}: \rho \mathrm{y} 2 \mathrm{x}=\rho \mathrm{y} 2 \mathrm{y} 1=0$

Sedangkan uji secara individual ditujukan oleh Tabel (Coefficients). Hipotesis penelitian yang akan diuji dirumuskan menjadi hipotesis statistik sebagai berikut:

$\mathrm{H}_{0} \quad: \beta_{1}, \beta_{2}, \beta_{3}=0$ (tidak signifikan)

$\mathrm{H}_{1} \quad: \beta_{1}, \beta_{2}, \beta_{3}>0$ (signifikan).

Pengujian hipotesis mediasi dilakukan dengan prosedur Uji Sobel (Sobel Test) yang dikembangkan oleh Sobel pada tahun 1982. Uji Sobel digunakan untuk menguji kekuatan pengaruh tidak langsung variabel country of origin $(\mathrm{X})$ terhadap variabel purchase intention $(\mathrm{Y})$ melalui variabel brand image $(\mathrm{M})$. Pengaruh tidak 
langsung variabel country of origin $(\mathrm{X})$ terhadap variabel purchase intention $(\mathrm{Y})$ melalui variabel brand image (M) dihitung dengan cara mengalikan koefisien jalur X terhadap M (a) dengan koefisien jalur M terhadap Y (b) atau ab. Standard error koefisien a dan b ditulis dengan $S_{a}$ dan $S_{b}$, besarnya standard error tidak langsung (indirect effect) ditulis dengan $\mathrm{S}_{\mathrm{ab}}$.

\section{HASIL DAN PEMBAHASAN}

Tabel 5.

Karakteristik Responden

\begin{tabular}{|c|c|c|c|c|}
\hline No. & Variabel & Klasifikasi & Jumlah (Orang) & Persentase \\
\hline \multirow{2}{*}{1.} & \multirow{2}{*}{ Usia (tahun) } & $\leq 30$ & 113 & 94 \\
\hline & & $>30$ & 7 & 6 \\
\hline \multicolumn{3}{|c|}{ Jumlah } & 120 & 100 \\
\hline \multirow{2}{*}{2.} & \multirow{2}{*}{ Jenis Kelamin } & Laki - Laki & 65 & 54 \\
\hline & & Perempuan & 55 & 46 \\
\hline \multicolumn{3}{|c|}{ Jumlah } & 120 & 100 \\
\hline \multirow{5}{*}{3.} & \multirow{4}{*}{ Pekerjaan } & Mahasiswa & 93 & 77 \\
\hline & & Pegawai & 13 & 11 \\
\hline & & Wiraswasta & 7 & 6 \\
\hline & & Lain - lain & 7 & 6 \\
\hline & \multicolumn{2}{|c|}{ Jumlah } & 120 & 100 \\
\hline
\end{tabular}

Sumber: Data primer diolah, 2018

Jumlah responden dalam penelitian ini adalah 120 orang. Tabel 5. menunjukkan bahwa sebagian besar responden berada pada klasifikasi usia $\leq 30$ tahun dengan persentase 94 persen dari total responden. Sedangkan pada responden dengan rentang usia > 30 tahun hanya dengan persentase 6 persen. Pembagian berdasarkan jenis kelamin responden menunjukkan bahwa laki-laki berjumlah 65 orang dengan persentase 54 persen, sedangkan perempuan berjumlah 55 orang dengan persentase 46 persen. Pekerjaan responden diketahui sebanyak 93 orang sebagai mahasiswa dengan persentase 77 persen, 13 orang sebagai pegawai dengan persentase 11 persen, 7 orang sebagai 
Ida Bgs Hendra Prawira Kusuma, Peran Brand Image Sebagai ...

wiraswasta dengan persentase 6 persen, serta sebanyak 7 orang sebagai lain - lain dengan persentase 6 persen.

Tabel 6.

Hasil Uji Validitas

\begin{tabular}{lllcc}
\hline No & Variabel & \multicolumn{1}{c}{ Indikator } & $\begin{array}{c}\text { Koefisien } \\
\text { Korelasi }\end{array}$ & Keterangan \\
\hline 1. & Country of Origin & Teknologi yang tinggi & 0,808 & Valid \\
& & Reputasi negara yang baik & 0,748 & Valid \\
& & Negara yang inovatif & 0,843 & Valid \\
& \multirow{4}{*}{ Brand Image } & Merupakan negara maju & 0,896 & Valid \\
& & Merek yang kuat & 0,916 & Valid \\
& & Coorporate image & 0,710 & Valid \\
& \multirow{3}{*}{ Purchase } & Product image & 0,888 & Valid \\
3. & Kemasan dan desain yang baik & 0,883 & Valid \\
& Intention & Kesadaran akan eksistensi produk & 0,741 & Valid \\
& & Ketertarikan untuk mencoba & 0,905 & Valid \\
& & Mencari informasi tentang harga & 0,932 & Valid \\
& & Keinginan segera membeli & 0,899 & Valid \\
\hline
\end{tabular}

Sumber: Data primer diolah, 2018

Uji validitas menunjukkan bahwa nilai koefisien korelasi dari masing-masing indikator memiliki nilai yang lebih besar dari 0,3. Korelasi tiap indikator tersebut bernilai positif $(r>0,3)$, maka instrumen yang digunakan dalam penelitian ini adalah valid.

Tabel 7.

Hasil Uji Reliabilitas

\begin{tabular}{lcc}
\hline \multicolumn{1}{c}{ Variabel } & Cronbach's Alpha & Keterangan \\
\hline Country of Origin & 0,895 & Reliabel \\
Brand Image & 0,868 & Reliabel \\
Purchase Intention & 0,878 & Reliabel \\
\hline Sumber: Data primer diolah, 2018 &
\end{tabular}

Hasil uji reliabilitas menunjukkan bahwa semua variabel yang digunakan memiliki nilai cronbach's alpha lebih besar dari 0,6. Keseluruhan indikator variabel dalam penelitian ini adalah reliabel yang artinya telah memenuhi syarat konsistensi maupun keandalan data, sehingga dapat digunakan sebagai instrumen penelitian.

Deskripsi data variabel menggambarkan penilaian dari pernyataan -pernyataan yang terdapat di dalam kuisioner penelitian. Rata - rata skor jawaban responden pada 
kuesioner dikelompokkan kedalam 5 kelas interval dengan formula sebagai berikut (Wirawan, 2002 : 35). Bobot penilaian dalam rentang nilai 1 sampai 5 akan di formulasikan ke dalam beberapa interval kelas berikut.

$$
\begin{array}{ll}
1,00-1,79 & =\text { Sangat Tidak Baik } \\
1,80-2,59 & =\text { Tidak Baik } \\
2,60-3,39 & =\text { Cukup Baik } \\
3,40-4,19 & =\text { Baik } \\
4,20-5,00 & =\text { Sangat Baik }
\end{array}
$$

Tabel 8.

Penilaian Responden terhadap variabel Country of Origin

\begin{tabular}{lccccccccc}
\hline \multicolumn{1}{c}{ Indikator } & \multicolumn{4}{c}{ Skor Jawaban } & Jumlah & Rata- & Keterangan \\
& & $\mathbf{1}$ & $\mathbf{2}$ & $\mathbf{3}$ & $\mathbf{4}$ & $\mathbf{5}$ & Skor & Rata & \\
\hline Teknologi yang tinggi $\left(\mathrm{X}_{1}\right)$ & 0 & 3 & 36 & 64 & 17 & 455 & 3,79 & Baik \\
Reputasi negara yang baik $\left(\mathrm{X}_{2}\right)$ & 0 & 1 & 30 & 69 & 20 & 468 & 3,90 & Baik \\
Negara yang inovatif $\left(\mathrm{X}_{3}\right)$ & 0 & 0 & 31 & 64 & 25 & 474 & 3,95 & Baik \\
Merupakan negara maju $\left(\mathrm{X}_{4}\right)$ & 0 & 1 & 37 & 62 & 20 & 461 & 3,84 & Baik \\
\hline \multicolumn{1}{c}{ Total } & & & & & $\mathbf{1 8 5 8}$ & $\mathbf{3 , 8 7}$ & \\
\hline
\end{tabular}

Sumber: Data primer diolah, 2018

Penilaian responden terhadap indikator-indikator dari variabel country of origin. Jawaban paling tinggi dari responden ditunjukkan pada indikator negara yang inovatif dengan nilai skor rata-rata sebesar 3,95. Nilai skor rata-rata paling rendah ditunjukkan pada indikator teknologi yang tinggi dengan nilai 3,79. Melihat data keseluruhan dari variabel country of origin, dapat ditentukan nilai skor rata-rata total sebesar 3,87. Nilai tersebut masuk ke dalam kriteria baik, sehingga dapat dinyatakan bahwa secara umum responden memiliki persepsi baik terhadap country of origin pada produk mobil merek Isuzu. 
Tabel 9.

Penilaian Responden terhadap variabel Brand Image

\begin{tabular}{lcccccccc}
\hline \multicolumn{1}{c}{ Indikator } & \multicolumn{9}{c}{ Skor Jawaban } & Jumlah & $\begin{array}{c}\text { Rata- } \\
\text { Skor }\end{array}$ & Keterangan \\
\cline { 2 - 6 } & $\mathbf{1}$ & $\mathbf{2}$ & $\mathbf{3}$ & $\mathbf{4}$ & $\mathbf{5}$ & & \\
Merek yang kuat $\left(\mathrm{M}_{1}\right)$ & 0 & 5 & 29 & 66 & 20 & 461 & 3,84 & Tinggi \\
Coorporate image $\left(\mathrm{M}_{2}\right)$ & 0 & 5 & 26 & 76 & 13 & 457 & 3,81 & Tinggi \\
$\begin{array}{l}\text { Product image }\left(\mathrm{M}_{3}\right) \\
\text { Kemasan dan desain yang }\end{array}$ & 0 & 5 & 26 & 74 & 15 & 459 & 3,83 & Tinggi \\
baik $\left(\mathrm{M}_{4}\right)$ & 0 & 5 & 36 & 63 & 16 & 450 & 3,75 & Tinggi \\
\hline \multicolumn{3}{c}{ Total } \\
\hline
\end{tabular}

Sumber: Data primer diolah, 2018

Penilaian responden terhadap indikator-indikator dari variabel brand image.

Indikator terkait merek yang kuat memiliki nilai skor rata-rata paling tinggi yaitu sebesar 3,84. Nilai skor rata - rata paling rendah ditunjukkan pada indikator kemasan dan desain yang baik dengan nilai 3,75. Melihat data keseluruhan dari variabel brand image, dapat ditentukan nilai skor rata-rata total sebesar 3,80. Nilai tersebut masuk ke dalam kriteria baik, sehingga dapat dinyatakan bahwa secara umum responden memiliki persepsi tinggi terhadap brand image pada produk mobil merek Isuzu.

Tabel 10.

Penilaian Responden terhadap variabel Purchase Intention

\begin{tabular}{lcccccccc}
\hline \multicolumn{1}{c}{ Indikator } & \multicolumn{4}{c}{ Skor Jawaban } & Jumlah & Rata- & Keterangan \\
& \multicolumn{1}{c}{} & $\mathbf{2}$ & $\mathbf{3}$ & $\mathbf{4}$ & $\mathbf{5}$ & $\begin{array}{c}\text { Skor } \\
\text { Rata }\end{array}$ & \\
\hline $\begin{array}{l}\text { Kesadaran akan eksistensi produk } \\
\left(\mathrm{Y}_{1}\right)\end{array}$ & 0 & 5 & 26 & 69 & 20 & 464 & 3,87 & Tinggi \\
Ketertarikan untuk mencoba $\left(\mathrm{Y}_{2}\right)$ & 0 & 8 & 33 & 63 & 16 & 447 & 3,73 & Tinggi \\
Mencari informasi tentang harga $\left(\mathrm{Y}_{3}\right)$ & 0 & 10 & 36 & 56 & 18 & 442 & 3,68 & Tinggi \\
Keinginan segera membeli $\left(\mathrm{Y}_{4}\right)$ & 0 & 16 & 41 & 48 & 15 & 422 & 3,52 & Tinggi \\
\hline \multicolumn{1}{c}{ Total } & & & & & & $\mathbf{1 7 7 5}$ & $\mathbf{3 , 7 0}$ & \\
\hline
\end{tabular}

Sumber: Data primer diolah, 2018

Tabel 10 menunjukkan penilaian responden terhadap indikator-indikator dari variabel purchase intention. Indikator terkait kesadaran akan eksistensi produk memiliki nilai skor rata-rata paling tinggi yaitu sebesar 3,87. Nilai skor rata-rata paling rendah ditunjukkan pada indikator keinginan segera membeli 
dengan nilai 3,52. Melihat data keseluruhan dari variabel purchase intention, dapat ditentukan nilai skor rata-rata total sebesar 3,70. Nilai tersebut masuk ke dalam kriteria baik, sehingga dapat dinyatakan bahwa secara umum responden memiliki persepsi tinggi terhadap purchase intention pada produk mobil merek Isuzu.

Tabel 11.

Hasil Analisis Jalur Persamaan Regresi 1

\begin{tabular}{|c|c|c|c|c|c|}
\hline \multirow[t]{2}{*}{ Model } & \multicolumn{2}{|c|}{$\begin{array}{l}\text { Unstandardized } \\
\text { Coefficients }\end{array}$} & \multirow{2}{*}{$\begin{array}{c}\begin{array}{c}\text { Standardized } \\
\text { Coefficients }\end{array} \\
\text { Beta }\end{array}$} & \multirow[t]{2}{*}{$\mathbf{t}$} & \multirow[t]{2}{*}{ Sig. } \\
\hline & B & Std. Error & & & \\
\hline \multirow{2}{*}{$\begin{array}{l}\text { (Constant) } \\
\quad \text { Country of Origin }\end{array}$} & 5,848 & 1,172 & & 4,989 & 0,000 \\
\hline & 0,605 & 0,075 & 0,597 & 8,081 & 0,000 \\
\hline
\end{tabular}

Sumber: Data primer diolah, 2018

Hasil analisis jalur substruktur 1 telah disajikan pada tabel 11 maka persamaan strukturalnya adalah sebagai berikut:

$$
\begin{aligned}
& M=\beta_{1} X+\varepsilon_{1} \\
& M=0,597 X+\varepsilon_{1}
\end{aligned}
$$

Tabel 12.

\begin{tabular}{|c|c|c|c|c|c|}
\hline \multirow[t]{2}{*}{ Model } & \multicolumn{2}{|c|}{$\begin{array}{c}\text { Unstandardized } \\
\text { Coefficients }\end{array}$} & \multirow{2}{*}{$\begin{array}{c}\begin{array}{c}\text { Standardized } \\
\text { Coefficients }\end{array} \\
\text { Beta } \\
\end{array}$} & \multirow[t]{2}{*}{$\mathbf{t}$} & \multirow[t]{2}{*}{ Sig. } \\
\hline & B & Std. Error & & & \\
\hline 1 (Constant) & 1,326 & 1,276 & & 1,039 & 0,301 \\
\hline Country of Origin & 0,207 & 0,092 & 0,180 & 2,247 & 0,027 \\
\hline Brand Image & 0,674 & 0,091 & 0,595 & 7,405 & 0,000 \\
\hline $\mathrm{R}_{2}^{2}: 0,514$ & \multicolumn{2}{|c|}{ F Statistik : 61,939 } & 0,000 & & \\
\hline
\end{tabular}

Hasil Analisis Jalur Persamaan Regresi 2

Hasil analisis jalur substruktur 2 telah disajikan pada tabel 12, maka persamaan strukturalnya adalah sebagai berikut:

$$
\begin{aligned}
& \mathrm{Y}=\beta_{2} \mathrm{X}+\beta_{3} \mathrm{M}+\varepsilon_{2} \\
& \mathrm{Y}=0,180 \mathrm{X}+0,595 \mathrm{M}+\varepsilon_{2}
\end{aligned}
$$


Ida Bgs Hendra Prawira Kusuma, Peran Brand Image Sebagai ...

Terdapat pengaruh langsung (direct effect), yaitu 1) Pengaruh variabel country of origin $(\mathrm{X})$ terhadap variabel brand image $(\mathrm{M})$ adalah sebesar $\beta_{1}=$ 0,597 ; 2) Pengaruh variabel country of origin (X) terhadap variabel purchase intention $(\mathrm{Y})$ adalah sebesar $\left.\beta_{2}=0,180 ; 3\right)$ Pengaruh variabel brand image $(\mathrm{M})$ terhadap variabel purchase intention $(\mathrm{Y})$ adalah sebesar $\beta_{3}=0,595$. Selain itu terdapat pengaruh tidak langsung (indirect effect) pengaruh variabel country of origin (X) terhadap variabel purchase intention $(\mathrm{Y})$ dengan variabel brand image (M) sebagai variabel mediasi, sebagai berikut: Pengaruh tidak langsung sebesar 0,355 dan pengaruh total sebesar 0,535 .

Hasil analisis jalur substruktur 1 dan substruktur 2 telah dihitung, maka dapat disusun model diagram jalur akhir. Nilai standard error dihitung terlebih dahulu sebelum menyusun model diagram jalur akhir dan memperoleh hasil pengaruh error $_{1}\left(\varepsilon_{1}\right)$ sebesar 0,802 dan pengaruh error $_{2}\left(\varepsilon_{2}\right)$ sebesar 0,697. Nilai koefisien determinasi total sebesar 0,688 yang berarti bahwa sebesar 68,8 persen variasi purchase intention dipengaruhi oleh variasi country of origin dan brand image, sedangkan sisanya sebesar 31,2 persen dijelaskan oleh faktor lain yang tidak dimasukkan ke dalam model.

Diperoleh nilai koefisien $\mathrm{F} \leq 0,05$ dengan koefisien signifikan $0,000 \leq 0,05$, sehingga $\mathrm{H}_{0}$ ditolak dan $\mathrm{H}_{1}$ diterima. Hasil tersebut menunjukkan bahwa country of origin dan brand image berpengaruh secara simultan dan signifikan terhadap purchase intention. Model persamaan struktural dalam penelitian ini telah memenuhi syarat goodness of fit melalui uji F. 
Perhitungan koefisien jalur secara parsial (individu) memperoleh hasil analisis pengaruh country of origin dengan brand image diperoleh nilai koefisien beta sebesar 0,597 dengan nilai signifikansi t $0,000<0,05$, sehingga $\mathrm{H}_{0}$ ditolak dan $\mathrm{H}_{1}$ diterima. Hasil tersebut mempunyai arti bahwa country of origin berpengaruh positif dan signifikan terhadap brand image. Hasil analisis pengaruh country of origin terhadap purchase intention diperoleh nilai koefisien beta sebesar 0,180 dengan nilai signifikansi t 0,000 $<0,05$, sehingga $\mathrm{H}_{0}$ ditolak dan $\mathrm{H}_{2}$ diterima. Hasil tersebut mempunyai arti bahwa country of origin berpengaruh positif dan signifikan terhadap purchase intention. Hasil analisis pengaruh brand image terhadap purchase intention diperoleh nilai koefisien beta sebesar 0,595 dengan nilai signifikansi t $0,000<0,05$, sehingga $\mathrm{H}_{0}$ ditolak dan $\mathrm{H}_{3}$ diterima. Hasil tersebut mempunyai arti bahwa brand image berpengaruh positif dan signifikan terhadap purchase intention.

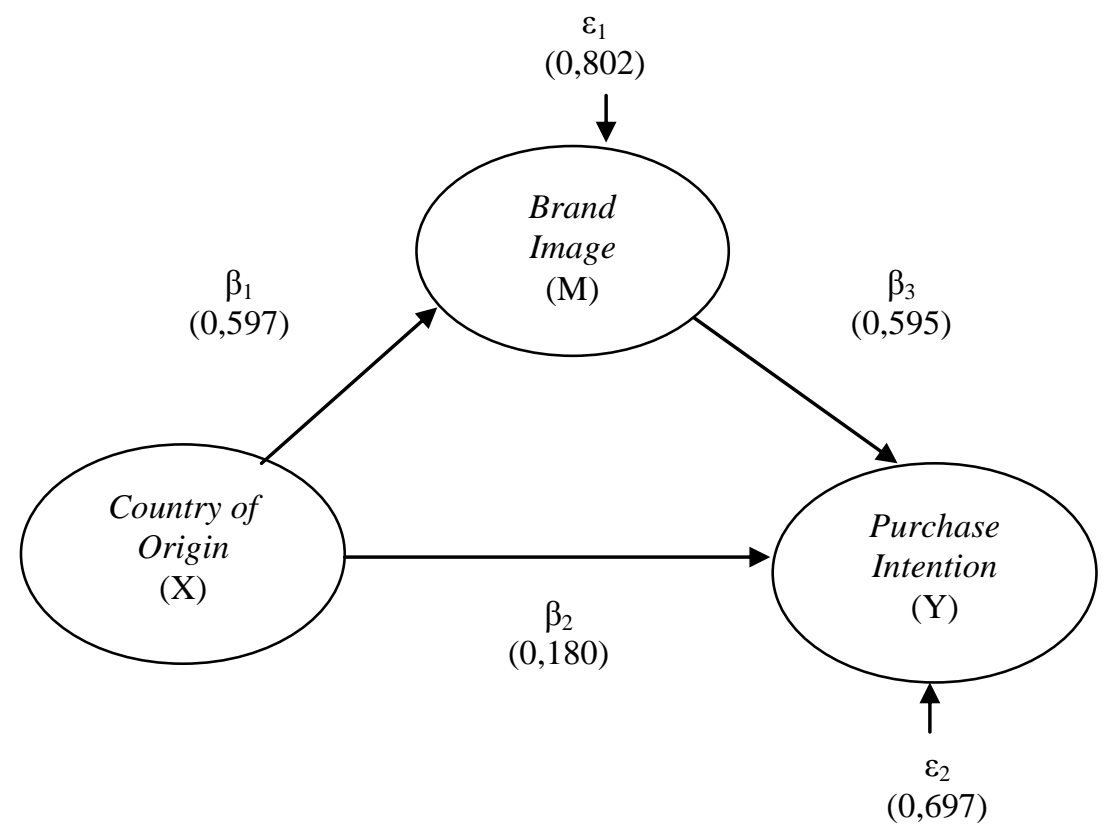

Gambar 3. Validasi Model Diagram Jalur Akhir

Sumber: Gambar diolah, 2018 
Tabel 13.

Pengaruh Langsung, Pengaruh Tidak Langsung serta Pengaruh Total Country of Origin (X), Brand Image (M) dan Purchase Intention (Y)

\begin{tabular}{lccc}
\hline Pengaruh Variabel & $\begin{array}{c}\text { Pengaruh } \\
\text { Langsung }\end{array}$ & $\begin{array}{c}\text { Pengaruh Tidak } \\
\text { langsung Melalui } \\
\text { Brand Image } \\
(\mathbf{M})=\left(\boldsymbol{\beta}_{\mathbf{1}} \times \boldsymbol{\beta}_{\mathbf{3}}\right)\end{array}$ & $\begin{array}{c}\text { Pengaruh } \\
\text { Total }\end{array}$ \\
\hline Country of Origin $\rightarrow$ Brand Image & 0,597 & - & 0,597 \\
\hline Country of Origin $\rightarrow$ Purchase Intention & 0,180 & 0,107 & 0,287 \\
\hline Brand Image $\rightarrow$ Purchase Intention & 0,595 & - & 0,595 \\
\hline Sumber: Data primer diolah, 2018 & & &
\end{tabular}

Pengaruh langsung variabel country of origin terhadap purchase intention memiliki nilai koefisien beta sebesar 0,180 , sedangkan pengaruh tidak langsung yang dimediasi oleh brand image menunjukkan nilai koefisien beta sebesar 0,107.

Hasil tersebut membuktikan bahwa brand image memediasi hubungan country of origin dengan purchase intention dengan pengaruh total yang diperoleh sebesar 0,287 .

Uji sobel dilakukan untuk menguji pengaruh tidak langsung variabel country of origin $(\mathrm{X})$ terhadap variabel purchase intention $(\mathrm{Y})$ melalui variabel brand image (M). Uji sobel dihitung dengan menggunakan aplikasi Microsoft Excel 2010. Hasil uji sobel menunjukkan bahwa nilai koefisien z adalah 5,65 > 1,96 sehingga $\mathrm{H}_{0}$ ditolak dan $\mathrm{H}_{4}$ diterima. Hasil tersebut memiliki arti bahwa brand image memediasi pengaruh country of origin terhadap purchase intention.

Pengaruh antara country of origin terhadap brand image telah diuji dalam penelitian ini, dimana nilai koefisien beta diperoleh sebesar 0,597 dengan tingkat signifikansi $0,000 \leq 0,05$ sehingga $\mathrm{H}_{0}$ ditolak dan $\mathrm{H}_{1}$ diterima, yang mengindikasikan bahwa country of origin berpengaruh positif dan signifikan terhadap brand image. Hasil tersebut menunjukkan bahwa semakin baik tingkat 
country of origin produk mobil merek Isuzu, maka semakin tinggi brand image pada produk mobil merek Isuzu di Kota Denpasar.

Pengaruh antara country of origin terhadap purchase intention dalam penelitian ini diperoleh nilai koefisien beta sebesar 0,180 dengan tingkat signifikansi $0,000 \leq 0,05$ sehingga $\mathrm{H}_{0}$ ditolak dan $\mathrm{H}_{2}$ diterima, yang mengindikasikan bahwa country of origin berpengaruh positif dan signifikan terhadap purchase intention. Hasil tersebut menunjukkan bahwa semakin baik tingkat country of origin produk mobil merek Isuzu, maka semakin tinggi purchase intention pada produk mobil merek Isuzu di Kota Denpasar.

Pengaruh antara brand image terhadap purchase intention dalam penelitian ini diperoleh nilai koefisien beta sebesar 0,595 dengan tingkat signifikansi $0,000 \leq$ 0,05 sehingga $\mathrm{H}_{0}$ ditolak dan $\mathrm{H}_{3}$ diterima, yang mengindikasikan bahwa brand image berpengaruh positif dan signifikan terhadap purchase intention. Hasil tersebut menunjukkan bahwa semakin tinggi tingkat brand image terkait produk mobil merek Isuzu, maka semakin tinggi pula purchase intention pada konsumen terkait produk mobil merek Isuzu di Kota Denpasar.

Peran brand image dalam memediasi country of origin terhadap purchase intention pada produk mobil merek Isuzu telah diuji dalam penelitian ini. Hasil uji pengaruh country of origin terhadap purchase intention semula bernilai 0,180 , kemudian setelah adanya brand image sebagai variabel mediasi, nilai pada pengaruh country of origin terhadap purchase intention meningkat menjadi sebesar 0,287. Uji sobel yang telah dihitung memperkuat hasil tersebut dengan nilai koefisien z yang diperoleh adalah 5,65 > 1,96 sehingga $\mathrm{H}_{0}$ ditolak dan $\mathrm{H}_{4}$ 
Ida Bgs Hendra Prawira Kusuma, Peran Brand Image Sebagai ...

diterima, yang mengindikasikan bahwa brand image memediasi pengaruh country of origin terhadap purchase intention. Hasil tersebut menunjukkan bahwa brand image dinilai mampu memediasi pengaruh country of origin terhadap purchase intention pada produk mobil merek Isuzu di Kota Denpasar.

\section{SIMPULAN DAN SARAN}

Berdasarkan pembahasan hasil penelitian, dapat ditarik simpulan bahwa Country of origin berpengaruh positif dan signifikan terhadap brand image yang menunjukkan semakin baik tingkat country of origin produk mobil merek Isuzu, maka semakin tinggi pula tingkat brand image terkait produk mobil merek Isuzu di Kota Denpasar. Country of origin berpengaruh positif dan signifikan terhadap purchase intention. Artinya bahwa semakin baik tingkat country of origin produk mobil merek Isuzu, maka semakin tinggi pula tingkat purchase intention terkait produk mobil merek Isuzu di Kota Denpasar. Brand image berpengaruh positif dan signifikan terhadap purchase intention. Artinya bahwa semakin tinggi tingkat brand image terkait produk mobil merek Isuzu, maka semakin tinggi pula tingkat purchase intention produk mobil merek Isuzu di Kota Denpasar. Peran brand image mampu memediasi secara signifikan hubungan country of origin dengan purchase intention. Artinya brand image dinilai mampu memediasi hubungan country of origin dengan purchase intention produk mobil merek Isuzu dilihat dari hasil yang diperoleh dari kedua teknik analisis yang berpengaruh positif dan signifikan. Saran bagi pihak Isuzu agar dapat mempertahankan ciri khas pada produknya yaitu sebagai raja mobil disel untuk menjaga brand image sehingga 
dapat berdampak pada timbulnya purchase intention konsumen terhadap produk mobil merek Isuzu dimasa mendatang. Selain itu terdapat saran bagi pihak Isuzu dalam mengenalkan produknya agar memberikan tampilan-tampilan baru dan harus juga mengetahui spesifikasi produk yang dibutuhkan oleh konsumen sehingga dapat meningkatkan brand image sekaligus mampu meningkatkan purchase intention dari calon konsumen dan bagi pihak Isuzu agar konsumen memiliki keinginan untuk mengetahui produk lebih lanjut, dengan mempromosikan produk di media cetak dan media lainnya sehingga menimbulkan niat untuk membeli.

\section{REFERENSI}

Arimbawa, N. A. C. dan I Ketut Rahyuda. 2015. Peran Brand Image Sebagai Mediator Antara Country Of Origin Terhadap Purchase Intention. E-Jurnal Manajemen Unud, 4(4): 879-897.

Adriyani, N., dan Sembriwing, B. K. 2012. Analisis Strategi Merek Dan Citra Merek Terhadap Keputusan Pembelian Pada J.co Donuts \& Coffee Cabang Cambridge City Square Medan. Media Informasi Manajemen, 1(2): 1-12.

Bhakar, S. S., S. Bhakar, S. Bhakar. 2013. Relationship Between Country Of Origin, Brand Image and Customer Purchase Intentions. Far East Journal of Psychology and Business, 10(2): 25-47.

Calvin dan Hatane Semuel. 2014. Analisa Pengaruh Brand Image, Brand Trust Dan Economic Benefit Terhadap Niat Pembelian Polis Asuransi Pt. Sequislife Di Surabaya. Jurnal Manajemen Pemasaran Petra, 2(1): 1-11.

Chih, C, Y., P. J. Lin dan C. S Chen. 2013. How Brand Image, Country Of Origin, and Self, Congruity Influence Internet Users, Purchase Intention. Society For Research, 41(4): 599-612.

Diamantopoulos, Bodo Schlegelmilch, Dayananda Palihawadana. 2011. The relationship between country of origin image and brand image as drivers of purchase intention. International Marketing Review, 28(5): 508-524. 
Fajrianthi dan Farrah, Z. 2005, Strategi Perluasan Merek dan Loyalitas Konsumen, Jurnal Fakultas Psikologi Universitas Airlangga, 7(3): 276-288.

Ghozali, Imam. 2013. Aplikasi Analisis Multivariate dengan Program IBM SPSS 2.1. Edisi 7. Semarang: Badan Penerbit Universitas Diponegoro.

Kotler, Philip. 2000. Manajemen Pemasaran. Jilid 1. Edisi Milenium. Jakarta: Prentice Hall International Edition.

Kotler, Philip and Keller, Kevin Lane. 2009. Marketing Management. 13th Edition. Pearson Education Inc.

Kinnear, Thomas C. 1995. Marketing Research: An Applied Approach. McGraw Hill Text.

Martinez, Briana. dan Soyong Kim. 2012. Predicting Purchase Intention for private sale sites. Emeraldinsight. pp: 1361-2026.

Maunaza, A. 2012. Pengaruh Brand image terhadap Niat Membeli Konsumen (Studi Pada Penerbangan Lion Air Sebagai Low Cost Carrier). Jurnal Fakultas Ilmu Sosial Dan Ilmu Politik Program Studi Ilmu Administrasi, 4(3): 18-21.

Mira, N. L. P. dan Ni Nyoman Kerti Yasa. 2015. Peran Brand Image Sebagai Pemediasi Pengaruh Country Of Origin Terhadap pada Brand Equity. Jurnal Manajemen, Strategi Bisnis dan Kewirausahaan, 1(9): 26-32.

Musay, F. P. 2013. Pengaruh Brand Image Terhadap Keputusan Pembelian. Jurnal Aministrasi Bisnis, 3(2): 1-7.

Nugroho, Riant. 2003. Kebijakan Publik, Formulasi, Implementasi dan Evaluasi. Jakarta : PT Elex Media Komputindo.

Parameswaran, R. dan Pisharodi, R.M. 1994. Facets of Country of Origin Image an Empirical Assesment. Journal of Advertising, 23(1): 43-56.

Permana, M. S. 2013. Pengaruh Country Of Origin Brand Image Dan Presepsi Kualitas Terhadap Intensi Pembelian Pada Merek. Jurnal Fakultas Ekonomi dan Bisnis Universitas Kristen Satya Wacana Salatiga, 15(6): 251-165.

Pujadi, Bambang. 2010. Studi Tentang Pengaruh Brand image Terhadap Minat Beli Melalui Sikap Terhadap Merek.

Rahma, Sheilla Eva. 2007. Analisis Pengaruh Kualitas Layanan dan Citra Merek Terhadap Minat Beli dan Dampaknya pada Keputusan Pembelian (Studi Pada Pengguna Telepon Seluler Merek Sony Ericson di Kota Semarang). 
Rahyuda, I Ketut., Yasa, I G. W., dan Yuliarmi, N. N. 2004. Metodologi Penelitian. Diktat Kuliah Fakultas Ekonomi. Denpasar: Universitas Udayana.

Rangkuti, F. 2009. Strategi Promosi yang Kreatif dan Analisis Kasus Integreted Marketing Communication. Jakarta: PT Gramedia Pustaka Utama.

Rezvani, S., G. J. Rezvani, M. S. Rahman, F. Fouladivanda, M. Habibi, S. Eghtebasi. 2012."A Conceptual Study on The Country of origin Effect on Consumer Purchase intention”. Asian Social Science; 8(12): 205.

Riduwan dan Kuncoro, Engkos Achmad. 2011. Cara Menggunakan dan Memaknai Analisis Jalur ( Path Analysis ). Bandung : Alfabeta.

Riezebos, R., Kist, B., Koostra. G. 2003. Brand Management: A Theoretical and Practical Approach. Prentice Hall.

Riyadi, Teguh. 2012. Cara Kerja dan Troubleshooting Sistem Bahan Bakar Isuzu Panther AJA1-L. Jurnal Teknik Mesin Fakultas Teknik Universitas Negeri Semarang, 5(2): 90-95.

Samuel, H. D. dan Suryanata Lianto 2014. Analisis Ewom, Brand Image, Brand Trust dan Minat Beli Produk Smartphone di Surabaya. Jurnal Manajemen Pemasaran, 8(2): 47-55.

Shah, S. S. H., J. Aziz, A. R. Jaffari, S. Waris, W. Ejaz, M. Fatima, K. Sherazi. 2012. The Impact of Brands on Consumer Purchase intentions. Asian Journal of Business Management, 4(2): 105-110.

Suprapti, N. W. S. 2010. Perilaku Konsumen: Pemahaman dasar dan aplikasinya dalam strategi pemasaran. Bali: Udayana University Press.

Susanti, R., D. H dan Kustijana. 2010. Efek Dari Country Of Origin dan Pengetahuan Produk Pada Evaluasi Produk dan Niat Pembelian Produk Sepeda Motor. Fakultas Ekonomi Universitas Sebelas Maret. Jurnal Ekonomi dan Kewirausahaan, 10(1): 1-10.

Sutisna. 2010. Perilaku Konsumen dan Komunikasi Pemasaran. PT. Remaja Rosdakarya, Bandung.

Sugiyono. 2012. Metode Penelitian Kuantitatif Kualitatif dan R\&D. Bandung: Aalfabeta.

2014. Metode Penelitian Bisnis (Pendekatan Kuantitatif, Kualitatif, dan $R \& D)$. Bandung: Alfabeta. 
Wahyuni, S. 2016. Pengaruh Country of Origin, Brand Image dan Persepsi Kualitas Terhadap Minat Beli Oppo Smartphone Studi Kasus Pada Mahasiswa Strata Satu Fakultas Ekonomi Universitas Negeri Yogyakarta. Journal Universitas Negeri Yogyakarta, 3(4): 122-134.

Wang, X., Z. Yang. 2008. Does Country of Origin Matter in The Relationship Between Brand Personality and Purchase Intention in Emerging Economies. Evidence from China's auto industry. International Marketing Review, 25(4): 458-474.

Wijaya, Bambang Sukma. 2011. The Development of Hierarchy of Effect Model in Advertising. International Research Journal of Business Studies, 5(1): 73-85.

Wirawan, Nata. 2002. Cara Mudah Memahami Statistik 1 (Statistik Deskripstif) Edisi 1. Denpasar : Keramat Emas.

Yasin, Norjaya Mohd, Noor, Mohd Nasser, Mohamad, Osman. 2007. Does image of Country of origin Matter to Brand equity. Journal of Product and Brand Management, 16(1): 38-48.

Yamen Koubaa. 2008. Country of origin, Brand image perception, and Brand image Structure Asia Pacific. Journal of Marketing and Logistics, 20(2): $139-156$.

Yu Chih-Ching, Pei-Jou Lin, And Chun-Shuo Chen. 2013. How Brand Image, Country Of Origin, And Self-Congruity Influence Internet Users Purchase Intention. Social Behavior And Personality, 41(4): 599-612. 